\title{
DÉCÈS DE PERSONNALITÉS ÉMINENTES DU MOUVEMENT
}

Le CICR a appris avec émotion le décès de Justice J. A. Adefarasin, président de la Ligue des Sociétés de la Croix-Rouge et du Croissant-Rouge de 1977 à 1981 et ancien président de la Croix-Rouge du Nigeria. Son élection à la tête de la fédération des Sociétés nationales de la Croix-Rouge et du Croissant-Rouge avait alors représenté une étape significative dans l'histoire de la Ligue, car elle symbolisait pleinement l'ouverture de celle-ci à l'esprit d'universalité qui a inspiré la Ligue depuis 1919.

Le juge Adefarasin avait su également faire bénéficier la Ligue de sa longue expérience au service de la Croix-Rouge et de ses qualités d'ouverture, de modération et d'altruisme qui en firent le type même de «l'Homme Croix-Rouge».

De même le CICR déplore-t-il la disparition à l'âge de 97 ans du $\mathbf{D}^{r}$ Pavle Gregoric, président honoraire à vie de la Croix-Rouge de Yougoslavie.

Médecin-hygiéniste hautement qualifié, puis membre du Parlement et ministre de la Santé, il travailla à mettre sur pied après la Seconde Guerre mondiale des services sanitaires de caractère préventif. Dans l'accomplissement de cette tâche, il bénéficia de l'active coopération de la Croix-Rouge de Yougoslavie dont il assuma la présidence de 1947 à 1967. Le $\mathrm{D}^{\mathrm{r}}$ Gregoric déploya une activité intense dans les domaines des secours en cas de désastre, de l'éducation sanitaire et de la coopération internationale. Il était lauréat de la Médaille Henry Dunant qui lui fut décerné en 1973.

Le CICR gardera un souvenir ému de ces deux grands serviteurs de la cause humanitaire. 